\title{
Prevalence of pneumonia associated with measles among infants and children hospitalized in Khyber Teaching Hospital Peshawar, KPK, Pakistan
}

\author{
Shahid Khan ${ }^{1}$, Jafar Iqbal' ${ }^{2}$, Muhammad Tayyeb ${ }^{3}$, Shah Fahad ${ }^{1}$, Amen \\ Ullah $^{1}$ and Hidayat Khan ${ }^{4 *}$ \\ 1. Department of Allied Health Sciences, Khyber Medical University, Peshawar-Pakistan \\ 2. Department of Cardiology,College of Medical Technology, Bacha Khan Medical College, Mardan-Pakistan \\ 3. Department of Anesthesia, College of Medical Technology, Bacha Khan Medical College, Mardan-Pakistan \\ 4. College of Medical Technology, Bacha Khan Medical College, Mardan-Pakistan \\ *Corresponding author's email: farhansf9@gmail.com \\ Citation \\ Shahid Khan, Jafar Iqbal, Muhammad Tayyeb, Shah Fahad, Amen Ullah and Hidayat Khan. Prevalence of pneumonia \\ associated with measles among infants and children hospitalized in Khyber Teaching Hospital Peshawar, KPK, \\ Pakistan. Pure and Applied Biology.Vol. 10, Issue 3, pp703-712. http://dx.doi.org/10.19045/bspab.2021.100072
}

\begin{tabular}{llll}
\hline \hline Received: 06/08/2020 & Revised: 29/10/2020 & Accepted: 10/11/2020 & Online First: 27/11/2020 \\
\hline \hline
\end{tabular}

\section{Abstract}

The current study aimed to assess the prevalence and potential risk factors associated with the occurrence of pneumonia among people of Khyber Pakhtunkhwa. Pneumonia is one of the leading causes of children age less than 5 years. Acute Respiratory Tract is one of the leading causes of Pneumonia; the ratio of death due to pneumonia is $50 \%$ more in developing countries. Air pollution, concrete fuel for food preparation are the major sources of respiratory Tract Infection (RTI). RTI can cause $42 \%$ of death around the world. Hemolytic streptococci have the organisms that most prevailing in the lungs cause of Pneumonia which can lead to measles. The present study highlights the prevalence in Khyber Pakhtunkhwa, $61.8 \%$ child, and 38.2\% was infants. Male and Female ratios were $31.4 \%$ and $68.6 \%$ respectively. The economic loss among poor families in percentage was high $60 \%$, whereas middle and high economic status families were $30 \%$ and $10 \%$ respectively. The occurrences of the percentage of rural and urban were about $51 \%$ and $49 \%$ respectively.

Keywords: Khyber teaching hospital; Measles; Pneumonia; Prevalence; Respiratory tract infection; Risk factors; Streptococcus

\section{Introduction}

Acute Respiratory Infections (ARIs) are the most common diseases worldwide and a leading cause of morbidity in developing populations mostly due to pneumonia in children having age less than 5 years [1]. Globally four million children aged less than 5 years about $31 \%$ of death is due to acute lower respiratory tract infection (ALRTI) [2]. Lower respiratory tract infection associated with deaths, half of million people are associated with the illness of measles and quarter $(1 / 4)$ of a million, correspondingly are related to pertussis and perinatal causes. The death ratio due to pneumonia illness is $10-50$ times more in developing countries therefore 
agreeable to generous improvement. A justifiable resolution to the problem of great mortality with ARI (acute respiratory infections) must be to initiate the stoppage of pneumonia [3].

Though, epidemiological records on the risk aspects for ARI in evolving countries are restricted [2]. Exposure to the outside and inside air pollutions has been situated suspected to raise the hazard of acute lower respiratory tract infection (ARTI) in many developing republics $[4,5]$. About half $(1 / 2)$ of the world depends upon biomass fuel, coal, and firewood which cause air pollution, $80 \%$ of wood is consumed in China and India [5]. The air pollution due to firewood and coal is an alarming risk of pneumonia and acute lower respiratory infection (ALRI) [5]. The odds ratio for acute lower respiratory tract infection (ALRTI) in four studies fluctuated from $2 \pm 2$ and $4 \pm 8 \mathrm{a}$ case management strategy of the World Health Organization (WHO) has been demonstrated [5]. The health workers who treated acute lower respiratory tract infections (ARTI) have reduced the death ratio by $42 \%$ in developing countries $[6,7]$. Due to the potential and efficacy of vaccine around the world still there have barriers and bias which have reduced sensitivity analyses of vaccine efficacy which increased the risk of infection [8]. An outbreak of measles in the Northern village of Pakistan, the vaccination program was launched $[9,10]$. An outbreak of measles occursin developing countries despite the accessibility of an active and harmless vaccine [11]. In 2001 when anout break of measles occurs in Japan which affects 286,000 individuals, much of them were less than 1 year and young children [12]. Since that time, the measles controller has been reinforced in Japan with the establishment by the Contagious Disease Surveillance Center (CDSC) of the measles scrutiny system and by the advancement of vaccination $[13,14]$. Pneumonia can be divided based on their severity into acute having exudate formation in the alveoli, fibrin being present always abundantly, while in chronic have interstitial bronchitis with remarkable changes in the interstitial tissue, have no exudate in the alveoli. This type was more prone to cause suppuration in the lungs and emphysema. Hemolytic Streptococcus is the causative agent of pneumonia [15]. Annually 935, 0002 and 2500 death per day occurs due to pneumonia in children having age less than 5 years [16]. Pneumonia causes (15\%) of all expiries in children in which $2 \%$ are newborns [17]. Ethiopia in the top 15 countries where pneumonia is an epidemic, it is the second leading cause of death in children younger than 5 years. About $20 \%$ of death occurs during the postnatal period and 40,000 children affected annually in Ethiopia [18-20].

India revealed that the overall prevalence of Acute Respiratory Infection (ARI) among less than five years was $4.5 \%$ in one month [21]. Bangladesh reported $21.3 \%$ of under five-year children suffered from Acute Respiratory Infection (ARI) [22].

Various Risk factors are associated with the occurrence of pneumonia. Such as environmental, health care facilities, overcrowding, indoor air pollution, Charcoal use for cooking, carrying the child on the back during cooking within the main house, Co-morbid diseases such as Human immunodeficiency virus HIV/ Acquired immunodeficiency syndrome (AIDS), Malaria, Exclusive breastfeeding, duration of breastfeeding as well as nutritional status of the child [23].

The most common investigation in Pakistan, especially in Khyber Pakhtunkhwa (Khyber Teaching Hospital Peshawar) is a chest X-ray to find any consolidation or patchy appearance and complete blood count to check any abnormal values. Moreover, Computed Tomography (CT) of the chest may be advised. Biopsies, Throat Swab, 
Sputum Culture are detectable markers of pneumonia investigation [24].

In hospitalized patients, the treatment for measles and measles associated pneumonia depends upon the condition of severity and complication the patient. Mostly supportive treatment is required to manage and decrease the severity of pneumonia and complication of measles [25]. The most significant complications are otitis media and bacterial pneumonia. Those patients who have severe complications like encephalomyelitis must be admitted for observation in the period when airborne transmission occurs in admitted children [26].

World Health Organization recommended vitamin A to the children who die with measles. The dose should be given based on their age. The measles vaccine is generally given administered with Mumps and Rubella vaccine (MMR). The vaccine is defensive if directed within three days of contact [25].

Few studies have been conducted on pneumonia associated with measles among infants. Therefore, the present study was designed to explore the predisposing factors responsible for the prevalence of pneumonia in Peshawar, Khyber-Pakhtunkhwa. The major objective of the present study was the prevalence of pneumonia in measles patients and give useful suggestions to the health department about their risk factors to make effective policy for its

Control in infants and childrens.

\section{Materials and Methods}

\section{Study design}

A cross-sectional study was conducted to find out the frequency of pneumonia associated with measles in infants and children hospitalized at Khyber Teaching Hospital Peshawar Khyber Pakhtunkhwa. The current study was conducted in children's A, wards. Children's A, ward further containing into HDU (High Dependency Unit), paeds Intensive Care Unit (ICU), transition chamber, side rooms, Neonatal Recovery Unit (NRU), and measles chamber. Study population and sample size

One hundred and seventy-eight (178) patients, Infants, and children both male and female hospitalize with measles diagnosed in children A, ward of KTH were included in this study.

\section{Sampling technique}

Convenient non-probabilistic sampling techniques were used to collect data from patients through a questionnaire.

\section{Inclusion exclusion criteria}

Infants and children patient diagnosed with measles admitted in Khyber teaching hospital children A, ward. While a child's other than measles beside ward A were excluded from this study.

\section{Data collection procedure}

Pneumonia associated questionnaires were prepared to find the frequency of pneumonia in measles positive cases among infants and children in Khyber teaching hospital Peshawar. The questionnaires include eight (8) questions and were filled by the patients. The questionnaire was collected separately from each patient. The attendant of the patients was brief about the aims and purposes of the research study before filling the questionnaire.

\section{Data analysis procedure}

All questionnaires were checked cautiously. All variable of the questionnaires is entering to the Statistical Package for Social Sciences (SPSS) version 22. All the variables which are including in the questionnaires were checked for every mistake. Descriptive statistics were applied to the data for the determination of percentages and frequencies. Cross-tabulated methods were used for data analysis.

\section{Results}

\section{Sample Size}

The study sample size was 178 of which 122 were male and 56 were female. An infant and 
child ratio was $1: 1.6$. The patients selected in this study had aged from 1 month to 12 years. Cases selected for the study have been clinically diagnosed, which have measles, admitted to Children A, ward at KTH, Peshawar, Khyber Pakhtunkhwa. The diagnosis of these patients was based on clinical examination and radiological findings.

(Table 1). Shows the total number of measles diagnosed patients, 68 were from the age group of infants and 110 were from the age group of the child.

In (Table 2) it shows that the male-female ratio was 2.2:1. In (Table 3 ) it shows economic status, the percentage of the poor family was $60 \%$, while middle and high economic status families were $30 \%$ and $10 \%$ respectively.
In (Table 4) it shows the percentage of the rural and urban family which were $51 \%$ and $49 \%$ respectively.

The (Table $5 \& 6$ ) show several siblings and no of a sibling having measles, respectively. In (Table 7) it shows the severity of the diseases in patients, in which 2 having mild, 72 had moderate and 104 patients having severe measles. In (Table 8) it shows the vaccination status of the patients in which 18 patients have vaccinated with dose 1, 30 are fully vaccinated and 16 patients are not sure vaccinated status while 114 patients are not vaccinated.

In (Table 9) it shows pneumonia associated with measles in which $60 \%$ were pneumonia positive while $40 \%$ were pneumonia negative.

Table 1. Age-wise distribution

\begin{tabular}{|c|c|c|c|}
\hline Parameter & Frequency & Percent & Cumulative Percent \\
\hline Child & 110 & 61.8 & 80.9 \\
\hline Infant & 68 & 38.2 & 100.0 \\
\hline Total & 178 & 100.0 & \\
\hline
\end{tabular}

Table 2. Gender wise distribution

\begin{tabular}{|c|c|c|c|}
\hline Parameter & Frequency & Percent \% & Cumulative Percent \% \\
\hline F & 56 & 31.4 & 31 \\
\hline M & 122 & 68.6 & 100.0 \\
\hline Total & 178 & 100.0 & \\
\hline
\end{tabular}

Table 3. Economic status

\begin{tabular}{|c|c|c|c|}
\hline Parameter & Frequency \% & Percent \% & Cumulative Percent \% \\
\hline HIGH & 18 & 10.2 & 55.1 \\
\hline Middle & 54 & 30.4 & 70.2 \\
\hline Poor & 106 & 59.6 & 100.0 \\
\hline Total & 178 & 100.0 & \\
\hline
\end{tabular}

Table 4. Residence

\begin{tabular}{|c|c|c|c|}
\hline Parameter & Frequency & Percent & Cumulative Percent \\
\hline Rural & 90 & 50.6 & 75.3 \\
\hline Urban & 88 & 49.4 & 100.0 \\
\hline Total & 178 & 100.0 & \\
\hline
\end{tabular}


Table 5. Number of siblings

\begin{tabular}{|c|c|c|c|c|c|}
\hline \multicolumn{6}{|c|}{ No. of siblings } \\
\hline \multicolumn{2}{|c|}{ Age } & Frequency & Percent & Valid Percent & Cumulative Percent \\
\hline \multirow{11}{*}{ Valid } & .0 & 13 & 7.3 & 14.6 & 14.6 \\
\hline & 1.0 & 9 & 5.1 & 10.1 & 24.7 \\
\hline & 2.0 & 19 & 10.7 & 21.3 & 46.1 \\
\hline & 3.0 & 10 & 5.6 & 11.2 & 57.3 \\
\hline & 4.0 & 19 & 10.7 & 21.3 & 78.7 \\
\hline & 5.0 & 6 & 3.4 & 6.7 & 85.4 \\
\hline & 6.0 & 5 & 2.8 & 5.6 & 91.0 \\
\hline & 7.0 & 6 & 3.4 & 6.7 & 97.8 \\
\hline & 8.0 & 1 & .6 & 1.1 & 98.9 \\
\hline & 9.0 & 1 & .6 & 1.1 & 100.0 \\
\hline & Total & 89 & 50.0 & 100.0 & \\
\hline Missing & System & 89 & 50.0 & & \\
\hline \multicolumn{2}{|c|}{ Total } & 178 & 100.0 & & \\
\hline
\end{tabular}

Table 6. No. of siblings with measles

\begin{tabular}{|c|c|c|c|c|c|}
\hline & & Frequency & Percent & Valid Percent & Cumulative Percent \\
\hline \multirow{7}{*}{ Valid } & .0 & 42 & 23.6 & 47.2 & 47.2 \\
\hline & 1.0 & 17 & 9.6 & 19.1 & 66.3 \\
\hline & 2.0 & 20 & 11.2 & 22.5 & 88.8 \\
\hline & 3.0 & 6 & 3.4 & 6.7 & 95.5 \\
\hline & 5.0 & 3 & 1.7 & 3.4 & 98.9 \\
\hline & 6.0 & 1 & .6 & 1.1 & 100.0 \\
\hline & Total & 89 & 50.0 & 100.0 & \\
\hline Missing & System & 89 & 50.0 & & \\
\hline \multicolumn{2}{|c|}{ Total } & 178 & 100.0 & & \\
\hline
\end{tabular}

Table 7. Measles severity

\begin{tabular}{|c|c|c|c|c|c|}
\hline \multicolumn{6}{|c|}{ Measles severity } \\
\hline & & Frequency \% & Percent \% & Valid \% & Cumulative \% \\
\hline \multirow{5}{*}{ Valid } & & 89 & 50.0 & 50.0 & 50.0 \\
\hline & MILD & 1 & .6 & .6 & 50.6 \\
\hline & Moderate & 36 & 20.2 & 20.2 & 70.8 \\
\hline & Severe & 52 & 29.2 & 29.2 & 100.0 \\
\hline & Total & 178 & 100.0 & 100.0 & \\
\hline
\end{tabular}

Table 8. Vaccination status

\begin{tabular}{|c|c|c|c|c|c|}
\hline \multicolumn{6}{|c|}{ Vaccination status } \\
\hline \multirow{4}{*}{ Valid } & Frequency \% & Percent \% & Valid \% & Cumulative \% \\
\cline { 2 - 6 } & NO & 18 & 10.1 & 10.1 & 10.1 \\
\cline { 2 - 6 } & not sure & 114 & 64.0 & 64.0 & 74.2 \\
\cline { 2 - 6 } & YES & 16 & 9.0 & 9.0 & 83.1 \\
\cline { 2 - 6 } & Total & 170 & 16.9 & 16.9 & 100.0 \\
\hline
\end{tabular}


Table 9. Pneumonia status of the patients

\begin{tabular}{|c|c|c|c|c|}
\hline \multicolumn{5}{|c|}{ Pneumonia } \\
\hline No & Frequency & Percent & Valid \% & Cumulative \% \\
\hline Yes & 72 & $40.4 \%$ & 40.4 & 40.4 \\
\hline Total & 106 & $59.6 \%$ & 59.6 & 100.0 \\
\hline
\end{tabular}

Among vaccine status and factor affecting vaccination (Fig. 1).

Shows pneumonia associated with measles in which $60 \%$ were pneumonia positive while $40 \%$ were pneumonia negative as shown in (Fig. 2).

Of total, pneumonia rate is high in poor families most of the cases were reported in poor socioeconomic status, while high economic status families reported less pneumonia cases as shown in (Fig. 3).

Of total, wheezing sound labeled in gray area while crepitation in blue area and participant with no abnormalities in breath sound labeled as a green as shown in (Fig. 4).

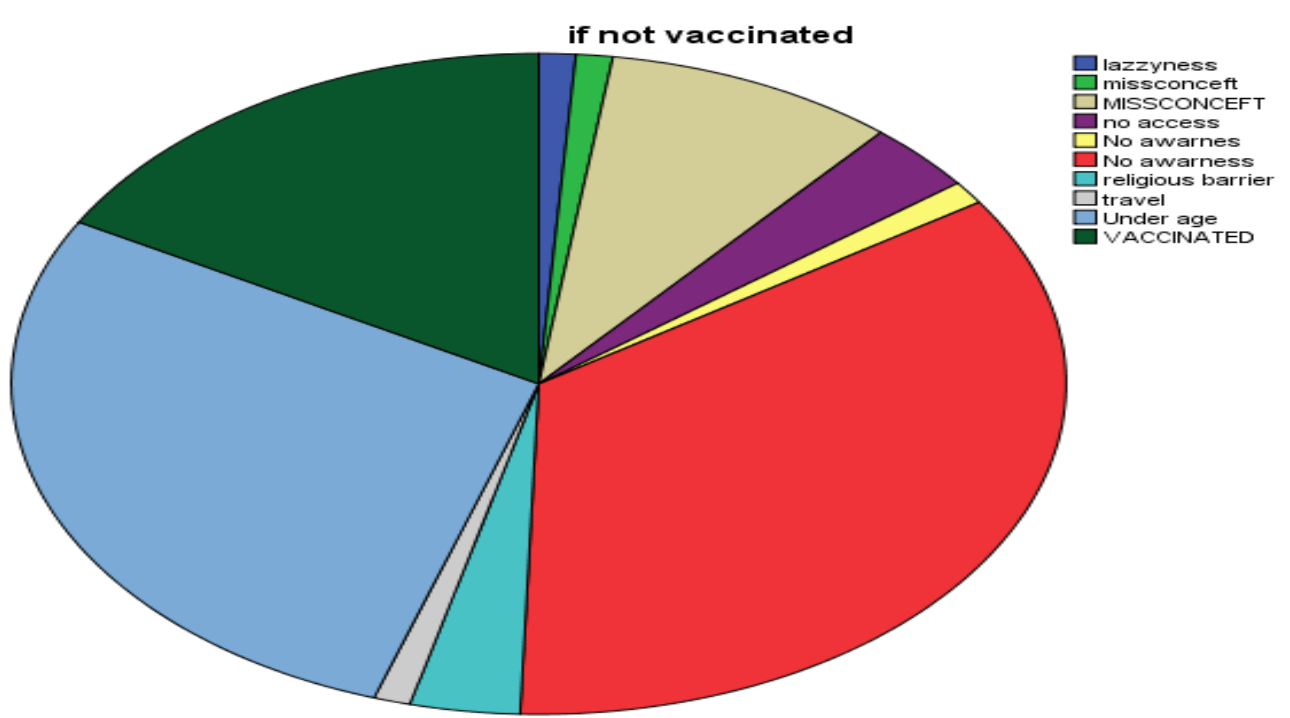

Figure 1. Vaccine status and factor affecting vaccination

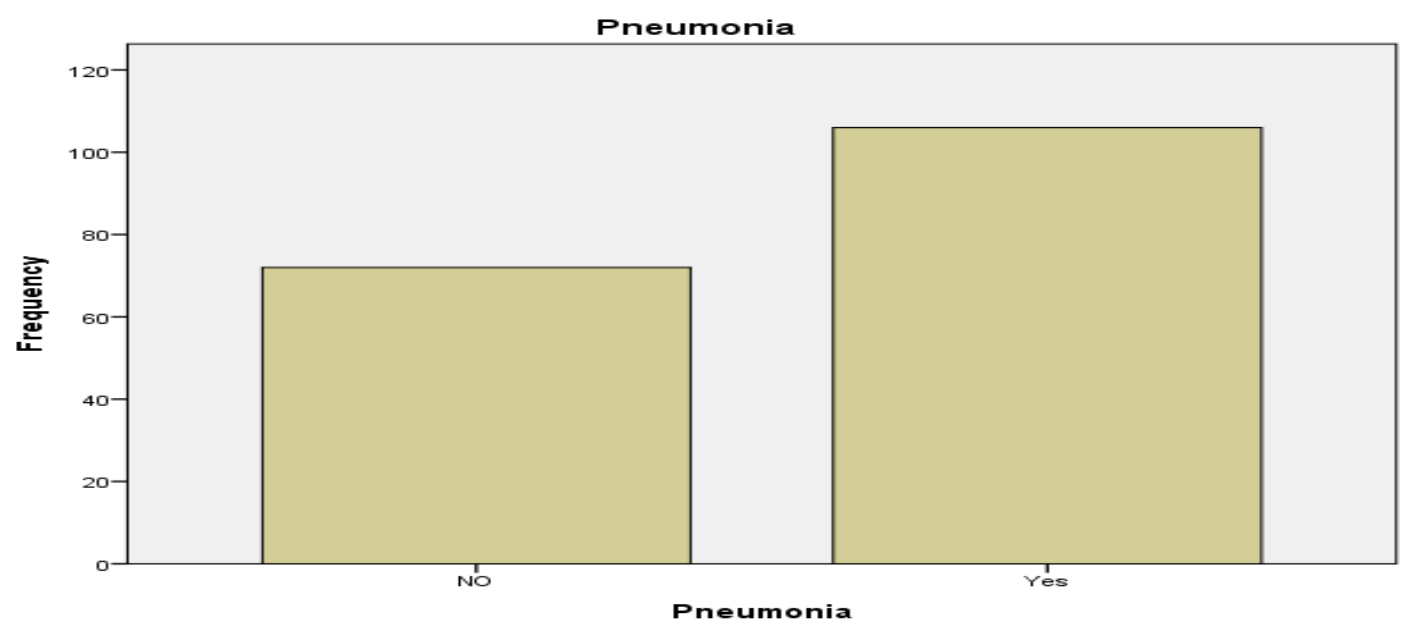

Figure 2. Frequency of pneumonia 


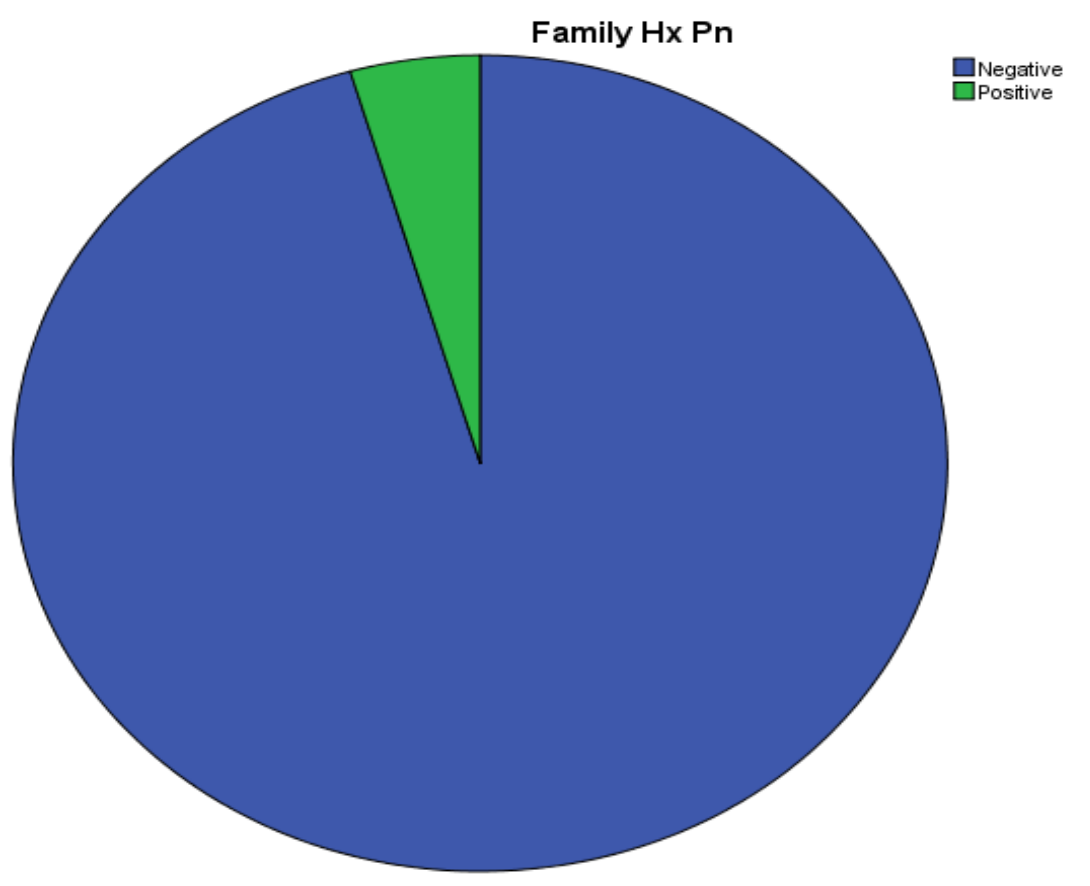

Figure 3. Pneumonia status in different socioeconomic family

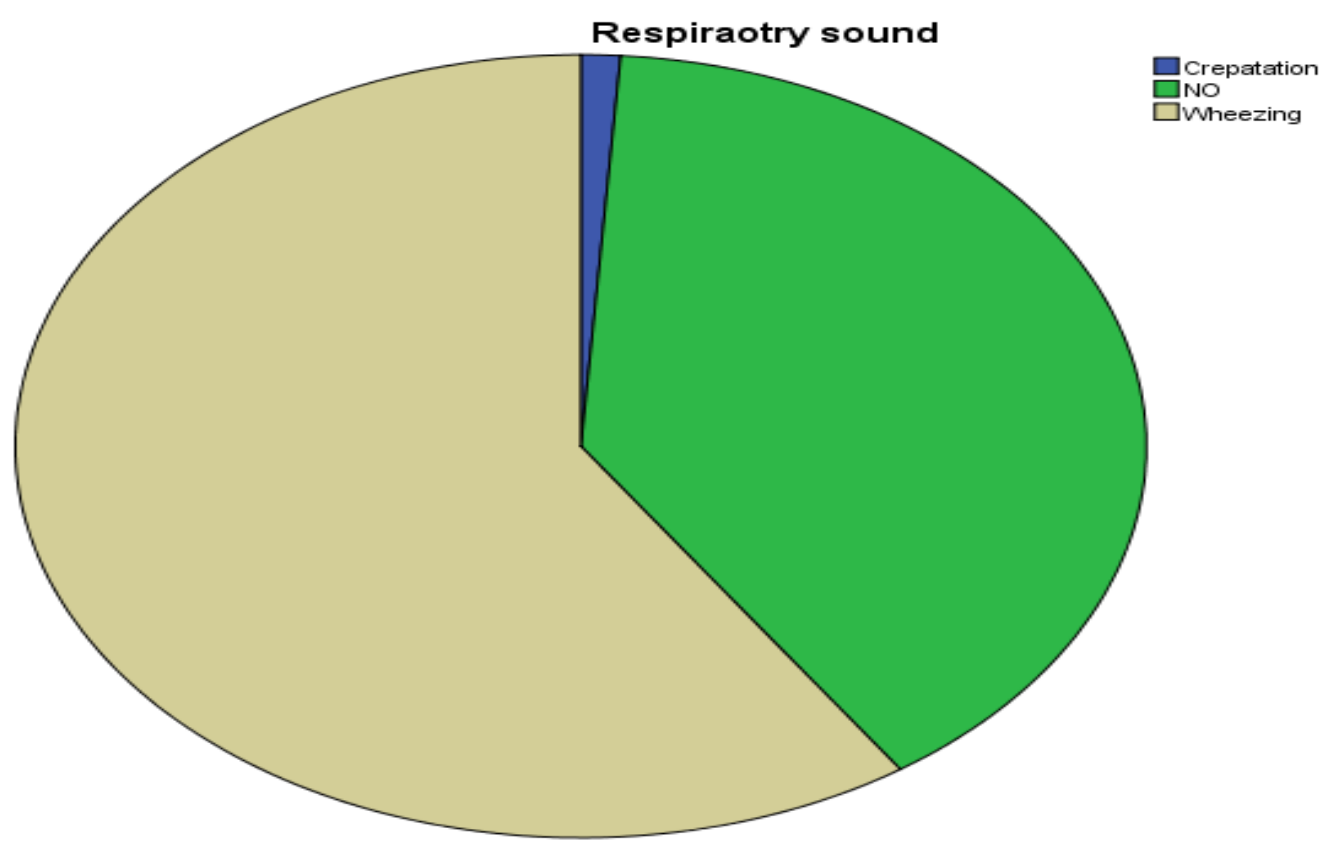

Figure 4. Status of auscultatory breath sounds

\section{Discussion}

The present study aimed to determine the risk factors of measles associated with pneumonia among children. Their direct burden of patients and their families during the infectious period. According to our study, $68.6 \%$ of male and $31.4 \%$ female patients who had complications aged 1 month to 12 
years were included. An almost a similar percentage was reported from another study in India, but their prevalence ratio was higher than our results which are $11.7 \%$ male and $51.5 \%$ were female respectively [25]. Our study co-relates to another study [25]. Our findings are also in line with the observation reported rate of measles among male and female children admitted at the hospital their results showed that $34.8 \%$ male and $47.8 \%$ were female patients [26]. A retrospective study in India conducted co-relate with our results [27]. A study performed at Peshawar showed that among patients' pneumonia was the main complication accounting for $68 \%$ [24]. Previously in a study conducted in Sweden find out that $75 \%$ of the patients having aged less than one-year have pneumonia. Pneumonia is more common among boys $40 \%$ than girls $21.5 \%$ [28].

The present study showed that the pneumonia rate is high in poor families, most of the cases $59.6 \%$ are poor socioeconomic status, the middle family had $30.4 \%$ and high economic status family were $10.2 \%$. Similar observations have been reported by others [29-32]. Our study is also supported by another study [33]. Our study is closed finding with the finding of [34].

The vaccination status of our study showed promising results which are $10.11 \%$ immunized with a single dose while $100 \%$ immunized with a complete course of vaccination. Our results co-relate to the study of [33]. Results have been reported from a study conducted in Karachi [35].

Our study reflects data only from a single health center it cannot represent the whole country. However, it can highlight the immunity gap. By the complication of this study, the health department will take mass immunization campaigns using the measles vaccine. Will be using live, attenuated measles vaccine for children having age 1 month to 12 years ago. It is hoped that this effort will eradicate the endemicity of measles in our region, but for complete eradication of these diseases, it is necessary routine immunization of new children's and epidemiologic surveillance in this area.

\section{Conclusion}

The main complication in measles patients is pneumonia followed by a loose motion. There is also some significant proportion of patients vaccinated with dose1 but who do not return for a second dose of the vaccine because they got measles before 15 months. This partially vaccinated problem must be noted for health planners. There is also a high proportion of no awareness for measles vaccination resulting in high rates of measles.

\section{Authors' contributions}

Conceived and designed the experiments: S Khan \& S Fahad, Performed the experiments: S Khan \& S Fahad, Analyzed the data: J Iqbal, M Tayyeb \& H Khan, Contributed materials/ analysis/ tools: A Ullah \& J Khan, Wrote the paper: H Khan.

\section{Acknowledgment}

This study has not been received any financial support from the Government or any Non-government organization. We are highly thankful to the Khyber Teaching Hospital staff for all their support and advice during this study.

\section{References}

1. World Health Organization. (1995). The World Health Report 1995: bridging the gaps. WHO.

2. Mahalanabis D, Gupta S, Paul D, Gupta A, Lahiri M \& Khaled MA (2002). Risk factors for pneumonia in infants and young children and the role of solid fuel for cooking: a case-control study. Epidemiol Infect 129(1): 65-71.

3. Victora CG, Kirkwood BR., Ashworth A, Black RE, Rogers S, Sazawal S \& Gove S (1999). Potential interventions for the prevention of childhood pneumonia in developing countries: improving nutrition. Am J Clin Nutr 7(3): 309-320. 
4. Chen BH, Hong CJ, Pandey MR \& Smith K R (1990). Indoor air pollution in developing countries. WHO Statistics Quarterly 43(3): 127-138.

5. Smith KR, Samet JM, Romieu I \& Bruce $N$ (2000). Indoor air pollution in developing countries and acute lower respiratory infections in children. Thorax 55(6): 518-532.

6. Fine PE \& Zell ER (1994). Outbreaks in highly vaccinated populations: implications for studies of vaccine performance. Am J Epidemiol 139(1): 77-90.

7. Haber M, Orenstein WA, Halloran ME \& Longini Jr IM (1995). The effect of disease prior to an outbreak on estimates of vaccine efficacy following the outbreak. Am J Epidemiol 14(10): 980990.

8. Chen RT, Weierbach R, Bisoffi Z, Cutts F, Rhodes P, Ramaroson S \& Bizimana F (1994). Apost-honeymoon period'measles outbreak in Muyinga sector. Int J Epidemiol. 23(1): 185-193.

9. McLean AR \& Anderson RM (1988). Measles in developing countries. Part II. The predicted impact of mass vaccination. Epidemiol Infect. 100(3): 419-442.

10. McLean AR (1994). Control of microparasites through vaccination. $J$ Parasit Dis 129-140.

11. Gomi H \& Takahashi H (2004). Why is measles still endemic in Japan. Lancet 364(9431): 328-329.

12. Centers for Disease Control and Prevention (CDC (2008). Progress toward measles elimination-Japan, 1999-2008. Mortal Wkly Rep 57 (38): 1049.

13. Kaetsu A, Miyazaki M, Matsumoto E, Sakamoto Y, Takano M, Imatoh T \& Une H (2008). An outbreak of measles in Saitama City in 2007. What is the vaccination strategy to eliminate measles in Japan. J Infect Chemother 14(4): 291295.

14. Nagano $H$, Jinushi $M$, Tanabe $H$, Yamaguchi R \& Okano M (2009). Epidemiological and molecular studies of measles at different clusters in Hokkaido district, Japan. 2007. Jpn J Infect Dis 62(3): 209-211.

15. Ellison JB (1931). Pneumonia in measles. Arch Dis Child 6(31): 37.

16. Abuka, $\mathrm{T}$ (2017). Prevalence of pneumonia and factors associated among children 2-59 months old in Wondo Genet district, Sidama zone, SNNPR, Ethiopia. Curr Pediatr Res 21(1): 19-25.

17. Liu L, Oza S, Hogan D, Perin J, Rudan I, Lawn JE \& Black RE (2015). Global, regional and national causes of child mortality in 2000-13, with projections to Inform post-2015 priorities: an updated systematic analysis. Lancet 385(9966): 430-440.

18. Martínez DE, \& Gibbons ED (2014). The questionable power of the Millennium Development Goal to reduce child mortality. J Hum Dev Capab 15(2-3): 203-217.

19. Deribew A, Tessema F \& Girma B (2007). Determinants of under-five mortality in Gilgel gibe field research center, Southwest Ethiopia. Ethiop J Health Dev 21(2): 117-124.

20. Gebremedhin, S (2014). Trend and socio-demographic differentials of Caesarean section rate in Addis Ababa, Ethiopia: analysis based on Ethiopia demographic and health surveys data. Reprod Health 11(1): 14.

21. Gupta RK, Kumar A \& Singh P (1999). Factor analysis of acute respiratory infections amongunder-fives in Delhi slums. Indian Pediatr 36(1): 1144-9.

22. Azad K, \& Muhammad AK (2009). Risk factors for acute respiratory infections (ARI) among under-five children in Bangladesh. J Sci Res 1(1): 72-81. 
23. Fatmi $\mathrm{Z} \&$ White F (2002). A comparison of 'cough and cold'and pneumonia: risk factors for pneumonia in children under 5 years revisited. Int $J$ Infect Dis 6(4): 294-301.

24. Ogbuanu IU, Zeko S \& Chu SY (2014). Maternal, fetal, and neonatal outcomes associated with measles during pregnancy: Namibia, 2009-2010. Clin Infect Dis 58: 1086.

25. Narain JP \& Banerjee KB (1989). Measles in India Epidemiology and control. Indian J Pediatr 56: 463-472.

26. Pongrithsukda VIM, Olmarn, Phonboon Kanchanasak \& Manunpichu, Krittaya (1986). Measles-associated diarrhoea in northeastern Thailand. Se Asian J Trop Med 17(1): 43.

27. Deivanayagam N, Mala N, ShaffiAhamed S \& Jagadish SV (1994). Measles associated diarrhea and pneumonia in south India. Indian Pediatr 31: 35-35.

28. Berglund A, Ekelund M, Fletcher MA \& Nyman L (2014). All-cause pneumonia hospitalizations in children $<2$ years old in Sweden, 1998 to 2012: impact of pneumococcal conjugate vaccine introduction. PLoS One 9(11): e112211.

29. Sato M, Tateishi, R, Yasunaga $H$, Horiguchi H, Yoshida H, Matsuda S \& Koike, K (2012). Mortality and morbidity of hepatectomy, radiofrequency ablation and embolization For Hepato cellular carcinoma: a national survey of 54,145 patients. J Gastroenterol Hepatol 47(10): 1125-1133.
30. Ahsan MR, Al Mamun A, Alam HSK, Sarker PK, Makbul S, Kabir R \& Al Mamun AMH (2018). Occurrence of Measles among Children Admitted in Tertiary Care Hospital. Bangladesh J. Child Health 42(1): 15-18.

31. Martins CL, Garly ML, Balé C, Rodrigues A, Ravn H, Whittle HC \& Aaby P (2008). Protective efficacy of standard Edmonston-Zagreb measles vaccination in infants aged 4.5 months: interim analysis of a randomized clinical trial. Bmj 337: a661.

32. Carabin H, Gyorkos TW, Soto JC, Penrod J, Joseph L \& Collet JP (1999). Estimation of direct and indirect costs because of common infections in toddlers attending day care centers. $J$ Pediatr 103(3): 556-564.

33. Pönkä A, Nurmi T, Salminen E \& Nykyri E (1991). Infections and other illnesses of children in day-care centers in Helsinki I: Incidences and effects of home and day-care center variables. $J$ Infect 19(4): 230-236.

34. Deivanayagam N, Mala N, Shaffi Ahamed S \& Jagadish Shankar V (1994). Measles associated diarrhea and pneumonia in south India. J Pediatr 31: 35-35.

35. Khowaja AR, Sheikh S, Saleem AF \& Zaidi AK (2015). Parental awareness and coverage of mass measles vaccination drive 2011: cross-sectional survey in the metropolitan city of Karachi, Pakistan. Asia-Pac J Public He 27(2): NP2749-NP2756. 